8. Sloan MA, Price TR, Randall AM, et al. Intracerebral hemorrhage after rt-PA and heparin for acute myocardial infarction: the TIMI II pilot and randomized trial combined experience. Stroke 1990;21:182

9. Kase CS, O'Neal AM, Fisher M, et al. Intracranial hemorrhage after use of tissue plasminogen activator for coronary thrombolysis. Ann Intern Med 1990;112:17-21

10. Cras P, Kawai M, Siedlak S, et al. Neuronal and microglial involvement in B-amyloid protein deposition in Alzheimer's disease. Am J Pathol 1990;137:241-246

11. Khachaturian ZS. Diagnosis of Alzheimer's disease. Arch Neurol 1985;42:1097-1105

12. Mark DB, Hlatky MA, O'Connor CM, et al. Administration of thrombolytic therapy in the community hospital: established principles and unresolved issues. J Am Coll Cardiol 1988;12: $32 A-43 A$

13. Vinters HV. Cerebral amyloid angiopathy a critical review. Stroke 1987;18:311-324

14. Ishii $\mathrm{N}$, Nishihara $Y$, Horie A. Amyloid angiopathy and lobar cerebral hemorthage. I Neurol Neurosurg Psychiatry 1984; $47: 1203-1210$

\section{Myoclonus in Adult Huntington's Disease}

Caryn M. Vogel, MD,* Ivo Drury, MB, BCh,*

L. Cass Terry, $\mathrm{MD}, \mathrm{PhD}, \dagger$

and Anne B. Young, MD, PhD*

Two brothers with clinically definite adult Huntington's disease developed disabling myoclonus years after the first signs of the disease. Their electroencephalograms were consistent with a primary generalized epilepsy, although neither man had seizures. The myoclonus was controlled with valproic acid therapy.

Vogel CM, Drury I, Terry LC, Young AB. Myoclonus in adult Huntington's disease. Ann Neurol 1991;29:213-215

Myoclonus is an uncommon clinical feature in Huntington's disease (HD). The prominent movement disorder in affected adults is chorea, whereas in juvenile patients, the clinical picture is one of parkinsonism $[1$, 2]. Only 3 patients with myocionus complicating adult HD have been reported [2-4], although the prevalence of myoclonus may be greater in patients with juvenile onset $[1,5]$. The parients described here illus-

From the *Department of Neurology, Universiry of Michigan Medical School, Ann Arbor, MI, and the $\$$ Department of Neurology, Medical College of Wisconsin, Milwaukee, WI.

Received Mar 19, 1990, and in revised form Jul 31. Accepted for publication Aug 2, 1990.

Address correspondence to Dr Vogcl, University of Michigan Medical Center, Department of Neurology, 1915 Taubman Center, 1500 East Medical Center Drive, Ann Arbor, MI 48109-0322. trate that myoclonus can be a disabling but treatable feature in a subset of patients with adult HD.

\section{Patient Histories}

T.T. was first evaluated at age 28 years, 2 years after the onset of cognitive decline and incoordination. The diagnosis of $\mathrm{HD}$ was supported by findings of dementia and choreiform movements, and a definite family history of adult onset dementia and chorea previously diagnosed as HD (Fig 1). Neuropsychometric testing revealed a full scale IQ (FSIQ) of 72 , and positron emission tomography (PET) demonstrated hypometabolism in the caudate nuclei. Ceruloplasmin, serum and urine copper levels, electroencephalogram (EEG), head computed tomographic (CT) scan, and cerebrospinal fluid (CSF) analysis were normal. Serial examinations over the next 5 years demonstrated only a mild cognitive decline until he presented with a 1-month history of uncontrollable brief, rapid jerking movements. Examination revealed frequent generalized myoclonic jerks involving axial and appendicular muscle groups, exacerbated by any attempt at movement, and prominent rigidity. Benztropine mesylate and haloperidol had been started after the onset of the myoclonus. These drugs were discontinued without clinical change.

A head CT scan showed prominent caudate atrophy. An EEG demonstrated generalized bisynchronous polyspike waves, at times associated with myoclonic jerks, without loss of consciousness and enhanced by photic stimulation (Fig 2). The myoclonus, as recorded by surface electromyography over the right forearm, consisted of 40 to 80 -msec bursts. The cortical component of short latency somatosensory evoked responses (SSERs) was not enlarged. An eccrine sweat gland biopsy for inclusion bodies, a periodic acid-Schiff stain for inclusion bodies in lymphocytes, an ophthalmological examination for a cherry red spot, and a lysosomal enzyme screen were negative. He did not cooperate with formal neuropsychometric testing.

Valproic acid was instituted daily with a pronounced reduction in myoclonus and a return to his previous level of function. Follow-up examination 5 months later revealed rare myoclonus and no polyspike-wave activity on EEG.

W.T., the older brother of T.T., was diagnosed with $\mathrm{HD}$ at age 30 years, 2 years after the onset of cognitive decline and involuntary movements. His initial evaluation was similar to his brother's except for caudate atrophy on head CT scan. Five years later, his caretakers reported a progressive decline in ambulation and recent onset of jerking movements that were worse on awakening. On neurological examination, any attempt to walk brought out myoclonic movements, which were otherwise infrequent. An EEG showed bisynchronous polyspike waves enhanced by photic stimulation. These appeared both independent of and concomitant with the myoclonus. The cortical component of the SSERs was not enlarged. Skin and rectal biopsies for inclusion bodies were negative by light and electron microscopy. Repeat neuropsychometric testing revealed a FSIQ of 64, with a pronounced decline in motor speed and dexterity. Five months after starting valproic acid therapy, he could walk unassisted; however, the remainder of his neurological examination, including the chorea, was unchanged. Follow-up EEG continued to show generalized polyspike waves. An EEG and SSERs were normal in a clinically unaffected brother. 


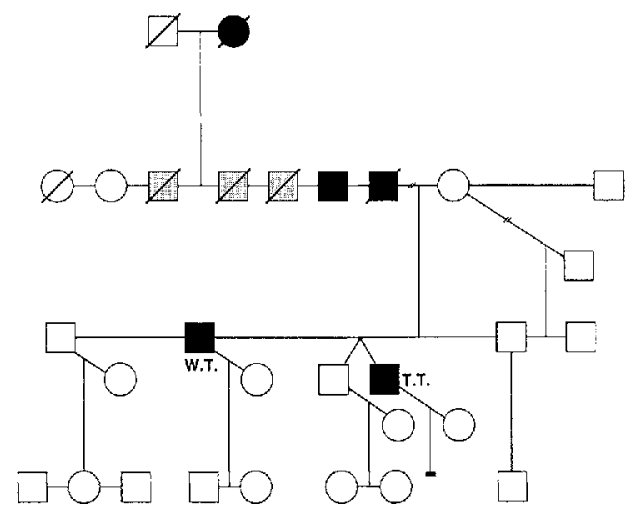

Fig 1. Family pedigree. Solid black squares $=$ definite Huntington's disease (HD); shaded squares $=$ possible $H D$.

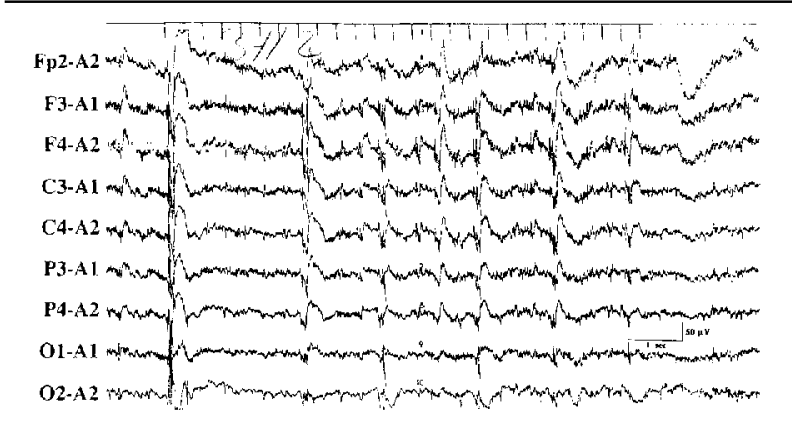

Fig 2. Generalized polyspike-wave discharges accentuated by photic stimulation in T.T. before treatment.

\section{Discussion}

These brothers are similar to the 3 previously reported patients with adult HD with myoclonus [2-4]. In all these patients, myoclonus was precipitated by the initiation of voluntary movement and often appeared as massive sudden jerks involving axial and appendicular muscle groups, and was easily controlled by either valproic acid or clonazepam. Each patient inherited HD from his father, and the onset of symptoms appeared in the third or early fourth decade.

Hereditary syndromes of myoclonus, dementia, and chorea comprise a rare and heterogenous group of disorders. In addition to HD, the differential diagnosis includes storage disorders (e.g., Lafora body disease, and neuronal ceroid lipofuscinosis and sialidosis), mitochondrial encephalomyopathies (e.g., myoclonic epilepsy and ragged red fibers, and "Tweed Ball" mitochondropathy), inborn errors of metabolism (e.g., glutaric acidemia, sulfite oxidase deficiency, and LeschNyham syndrome), Wilson's disease, chorea-acanthocytosis, and a few clinically or pathologically defined progressive myoclonic epilepsies (Unverricht-Lundborg disease, May-White syndrome, HallervordenSpatz disease, dentatorubralpallidoluysian atrophy, neuronal axonal dystrophy, action myoclonus-renal failure syndrome [5-8]). These brothers, however, lacked the inheritance pattern and clinical, laboratory, or pathological findings specific to these disorders. The autosomal dominant transmission, adult onset of chorea and dementia, and highly characteristic PET and CT findings strongly support $\mathrm{HD}$ as the clinical diagnosis in this family and the previously reported patients.

The electrophysiological features present in these patients are most consistent with reticular reflex myoclonus, which has been characterized as a fragment of generalized epilepsy [9]. There was an identifiable EEG correlate in the form of generalized polyspike waves that was not time-locked to the myoclonus. The cortical component of the SSERs was normal. Although these brothers did not have generalized seizures, their EEGs were similar to those seen in patients with a primary generalized seizure disorder, and 2 of the 3 previously reported parients with adult HD with myoclonus had documented seizures. Seizures occur rarely in patients with adult $\mathrm{HD}$, compared with twothirds of the patients with juvenile HD [1].

Deficiencies in gamma-aminobutyric acid (GABA) activity may play a role in the pathogenesis of some types of myoclonus. Reduced levels of GABA are present in the CSF of patients with postanoxic myoclonus and progressive myoclonic epilepsies compared with controls consisting of patients suffering from other neurological disorders $[10,11]$. The photosensitive myoclonus in the Senegalese baboon Papio papio can be blocked by gamma-acetylenic GABA and gamma-vinyl $G A B A$, irreversible inhibitors of the degrading enzyme, GABA-transaminase [12]. The manipulation of GABA activity in the contralateral striatum of rats results in sustained focal myoclonic jerks [13]. Clonazepam and valproic acid, effective treatments of myoclonus due to diverse pathologies, exert their therapeutic effects at least in part by influencing the GABA system [14].

In patients with rigid or juvenile onset $\mathrm{HD}$, the denervation in the substantia nigra pars reticulata is profound [15]. Bilateral lesions of the reticulata or inhibition of the reticulata neurons by GABA agonists attenuate kindled seizures in rats [16]. Stimulation of the substantia nigra pars reticulata neurons or injection of GABA antagonists lower the seizure threshold in a similar animal model [17]. This loss of nigral inhibition from the striatum may play a role in the susceptibility to myoclonus or seizures of some patients with HD.

If deficiencies in GABA are central to the pathogenesis of both HD and some forms of myoclonus, it is unclear why myoclonus is so infrequent in adult $\mathrm{HD}$. $\mathrm{HD}$ is genetically homogeneous, with the gene localized to the short arm of chromosome 4 [18]. Further studies will be necessary to elucidate why this population of patients with HD manifests a different expression of the same gene. Myoclonus should be 
recognized as a treatable feature in some patients with adult HD.

C.M.V. is a recipient of National Institutes of Health Training Grant 5-732 NS-07222.

Presented in part at the 114th Annual Meeting of the American Neurological Association, New Orleans, LA, September 1989.

\section{References}

1. Jarvis GA. Huntington's chorea in childhood. Arch Neurol 1963;9:244-257

2. Novum S, Danna S, Goldberg MA. Intention myoclonus in Huntington's disease. Bull LA Neurol Sci 1976;41:82-84

3. Kereshi S, Schlagenhauff RE, Richardson KS. Myoclonic and major seizures in early adult Huntington's chorea: case-report and electrocinical findings. Clin Electroencephalogr 1980;11: $44-47$

4. Previdi P, Borgonovi R. Myoclonus and Huntington's chorea: description of a case. Ital J Neurol Sci 1980;3:189-192

5. Berkovic SF, Andermann F, Carpenter L, Wolfe LS. Progressive myoclonus epilepsies: specific causes and diagnosis. $\mathrm{N}$ Engl J Med 1986;315:296-305

6. LeWitt PA, Truong DD, Hashimoto K, et al. "Tweed Ball" mitochondropathy with a unique neurodegenerative disorder. Ann Neurol 1989;26:122

7. Leibel RL, Shih VE, Goodman SI, et al. Glutaric acidemia: a metabolic disorder causing progressive choreoathetosis. Neurology 1980;30:1163-1168

8. Shibasaki H, Sakai T, Nishimura H, et al. Involuntary movements in chorea-acanthocytosis: a comparison with Huntington's chorea. Ann Neurol 1982;12:311-314

9. Hallett M. Myoclonus: relation to epilepsy. Epilepsia 1985; 26(suppl 1):S67-S77

10. Enna SJ, Ferkany JW, Van Woert M, Butler IJ. Measurement of GABA in biological fluids: effect of GABA transaminase inhibitors. In: Chase TN, Wexler NS, Barbeau A, eds. Adv Neurol, vol 23. New York: Raven Press, 1979:741-750

11. Airaksinen EM, Leino E. Decrease of GABA in the cerebrospinal fluid of parients with progressive myoclonus epilepsy and its correlation with the decrease of 5 HIAA and HVA. Acta Neurol Scand 1982;66:666-672

12. Meldrum B, Horton R. Blockade of epileptic responses in the photosensitive baboon, Papio papio, by two irreversible inhibitors of GABA-transaminase, gamma-acetylenic GABA 4amino-hex-5-ynoic acid and gamma-vinyl GABA (4-amino-hex5-enoic acid). Psychopharmacology 1978;59:47-50

13. Tarsy D, Pycock CJ, Meldrum BS, Marsden CD. Focal contralateral myoclonus produced by inhibition of GABA action in the caudate nucleus of rars. Brain 1978;101:143-162

14. Van Woert MH, Rosenbaum D, Chung E. Biochemistry and therapeutics of posthypoxic myoclonus. In: Fahn S, Marsden CD, Van Woert MH, eds. Adv Neurol, vol 43. New York: Raven Press, 1986:171-182

15. Albin RL, Reiner A, Anderson $\mathrm{KD}$, et al. Striatal and nigral subpopulations in rigid Huntington's disease: implications for the funcrional anatomy of chorea and rigidity. Ann Neurol $1990 ; 27: 357-365$

16. Garant DS, Gale K. Lesions of the substantia nigra protect against experimentally induced seizures. Brain Res 1983;273: $156-161$

17. Bonhaus DW, Walters JR, McNamara JO. Activation of substantia nigra neurons: role in the propagation of seizures in kindled rats. J Neurosci 1986;6:3024-3030

18. Gusella JF, Wexler NS, Conneally PM, et al. A polymorphic DNA marker genetically linked to Huntington's disease. Nature 1983;306:234-238

\section{Continuous Muscle Fiber Activity, Peripheral Neuropathy, and Thymoma}

A. García-Merino, MD,* A. Cabello, MD, $\dagger$ J. S. Mora, MD, ${ }^{*}$ and H. Liaño, MD*

Two patients, one of them with myasthenia gravis, presented symptoms of continuous muscle fiber activity syndrome before discovery of a thymoma. Peripheral neuropathy was present in both patients, with axonal and demyelinating lesions in sural nerve biopsy. The syndrome remained unchanged or worse after thymectomy. Both patients died of associated complications.

García-Merino A, Cabello A, Mora JS, Liaño $H$. Continuous muscle fiber activity, peripheral neuropathy, and thymoma.

Ann Neurol 1991;29:215-218

The syndrome of continuous muscle fiber activity at rest (CMFAS) [1] associates a wide spectrum of clinical manifestations with spontaneous electromyographic (EMG) discharges. The condition is a polymorphous entity described under various names such as neuromyotonia, pseudomyotonia, Isaacs' syndrome, and CMFAS [2]. We report here two patients with CMFAS, thymoma, and peripheral neuropathy, an associarion previously not recognized. The purpose of this report is to draw attention to the possible relevance of thymoma in the pathogenesis of the syndrome.

\section{Patient Reports}

\section{Patient 1}

A 56-year-old, previously healthy woman began to note facial twitching, blurred vision, occasional trismus, and soon after, vague thoracic discomfort. Six months after onset of symptoms, a large lymphoepithelial thymoma was found and resected. A few days after surgery, she developed profuse sweating, widespread muscle twitching, dyspnea, and carpal spasns. Serum calcium and magnesium were normal and intravenous calcium did not modify the spasms, which were only relieved by diazepam. Her condition deteriorated progressively. Her dyspnea became present on minimal effort and she developed laryngeal stridor. Extensor spasms of the

From the *Department of Neurology, Clínica Puerta de Hierro, Universidad Autónoma de Madrid, and the †Deparment of Neuropathology, Hospital "12 de Octubre," Madrid, Spain.

Received Jul 27, 1989, and in revised form Apr 2, Jul 24, and Aug 27, 1990. Accepted for publication Aug 30, 1990.

Address correspondence to Dr García-Merino, Departamento de Neurología, Clínica Puerta de Hierro, San Martín de Porres, 4, 28035 Madrid, Spain. 